Editorial

\title{
A special issue on model-based long-term transport scenarios: Model comparison and new methodological developments to improve energy and climate policy analysis
}

\section{Introduction}

Developments in the transport sector are very important for future climate change. First, global transport-related greenhouse (GHG) emissions are growing faster than any other end-use sector (Sims et al., 2014), partly related to the continuing growth of transport demand, including consumers' ever-increasing desire to travel by faster modes (Schäfer, 2009; Sims et al., 2014; IEA, 2016). Second, previous studies have emphasized that it is relatively difficult (i.e. more costly) to significantly reduce transport sector emissions: for several subsectors, such as air transport and freight, where few mitigation options have been identified (Sims et al., 2014). Although alternative propulsion technologies could certainly help to lower GHG emissions of road transport significantly (Kromer and Heywood, 2007), path dependency of infrastructure and behavioral barriers can slow down, if not prevent, a major transformation of the sector. Having said that, the potential for behavioral and lifestyle changes in other areas, such as modal shifts or avoided travel, could potentially be larger than currently indicated by the scenario literature (Banister, 2011; Creutzig et al., 2015).

Model-based scenario studies form a key tool to explore different decarbonization strategies (see Clarke et al. (2014)). Integrated assessment models (IAMs) and energy-economy models have been developed to explore the costs of different mitigation strategies and the interactions across the different sectors in a systems analytical manner. In recent years, these models have started to pay more attention to representing key energy demand sectors in greater detail, including the transport sector. This means that these models are able to provide insights into the possible long-term development of the global transport sector in the absence of stringent climate policy, but also possible pathways for countries' transport systems while meeting the deep emission reduction targets of the Paris Climate Agreement. The advantage of integrated assessment models and energy-economy models is that the scenarios derived from them consider interactions of the transport system with other sectors. This, for instance, includes the constrained availability of biofuels (as inherently limited amounts of biomass can also be used as feedstock in the power sector), the depletion of oil, and future climate targets for different sectors in "cost-effective" strategies.

In addition to economy-wide models, however, also detailed transport sector-only models exist, in which sector-specific policies to reduce emissions (e.g. vehicle taxation, parking fees, fuel economy standards) and infrastructural and behavioral considerations are implemented in more detail. Due to the large scale (spatial and temporal) of the analysis of integrated assessment models, they have historically had a limited ability to represent this kind of detail; however, as this special issue shows, efforts have been made to model such relationships, sometimes with quite explicitly and sometimes in a more stylized manner, in order to capture key dynamics that may impact the projected transport mitigation pathways.

In this Special Issue, we first of all document some recent model developments - by looking into the individual models and associated applications. These include, for instance, the issue of how to deal with consumer behavior or the role of infrastructure. In addition, we also present several model comparison studies. Model comparison is a tool that has long been used to better understand the robustness of model outcomes, to understand uncertainty, and also to identify critical areas where models could be enhanced (Kriegler et al., 2015). Thus far, only a few model comparison studies have been conducted focusing on the transport sector outcomes of integrated models (Girod et al., 2013; Pietzcker et al., 2014). The studies presented here utilize more detailed decomposition methods to explore underlying trends, inputs and key assumptions, covering different sets of models, and comparing IAMs to transport sector-only models. 


\section{New model development}

This Special Issue contains five papers that describe the development of new transport sector models/modules or insights that can lead to a better representation of transport in IAMs and other models.

The paper by McCollum et al. (2017) look specific at the role of heterogeneous consumer behavior in light-duty vehicle (passenger car and truck) purchasing decisions. Earlier studies have shown that such decisions, which collectively across a society have enormous energy and emissions implications, are often based on considerations other than costs, such as the vehicle's driving range and novelty, among others. The importance of these different factors varies significantly between different consumer groups - from early to late adopters or from urban consumers that drive relatively little to rural consumers who drive very frequently. Representing this consumer heterogeneity and behavior is therefore important for modelling future transport transitions. For these reasons McCollum et al. (2017) assess the impacts of introducing an innovative approach for modelling vehicle choices in the IAM MESSAGE-Transport, accounting for consumer preferences with respect to vehicle novelty, range, refueling/recharging station availability, and model variety. These preferences differ by vehicle type (conventional vs. advanced vehicles) and country/culture, and they are impacted critically by contextual factors (such as enabling infrastructure and whether others in the community have already adopted or not). The study shows that the response of the model including these factors differs significantly from the model that does not include them. A key insight from the exercise is that IAMs incorporating heterogeneous behavioral features are able to examine a more diverse suite of policy measures and instruments.

In a second paper, Karkatsoulis et al. (2017) include comprehensive transport sector modelling within a CGE framework (GEM-E3). The authors describe how such transport sector detail can be included, and present the findings of their improved set-up. The model shows that decarbonizing the transport sector in Europe leads to small negative impacts on the GDP of the EU. These effects are due to higher levelized cost of transport in the transition period. The deployment of advanced vehicle technologies is necessary for decarbonization but increases adjustment costs. The costs of batteries for electric vehicles are a significant factor influencing costs that need to be paid by households. Existence of versatile financing schemes eases the overall economic adjustment, while lack of financing instruments increases costs.

A third paper discusses the introduction of a road freight model into the aggregated integrated assessment model WITCH (Carrara and Longden, 2017). The study shows that freight transport is a relatively difficult sector for climate policy to address. Notable decarbonization is likely to take place only in the second part of the century, and only if strong mitigation policies are implemented. Even in these cases, freight transport decarbonization rates are found to be lower than for the rest of the economy.

Mittal et al. (2017) present a transport model which is part of the Integrated Assessment Modelling framework AIM and includes behavioral and technological features of 17 world regions. They apply the model to look into global transport demand, energy and emissions up to 2100. Moreover, they also explore the sensitivity of the model results to the assumed travel time, energy efficiency, load factor, mode preference and carbon taxes. They find that vehicle occupancy rates, mass transit system availability and carbon taxes are key to reduce energy and emissions.

Finally, Broin and Guivarch (2017) describe an exercise where the costs of infrastructure deployment for the transport sector have been incorporated into the IMACLIM-R global E3 IAM. This addition and the recalibration of the existing formulation of infrastructure resulted in a better representation of historically observed data (2001-2013) for investments in energy demand, road infrastructure, and passenger-kilometers travelled in the model. The model shows that if the deployment of infrastructure for roads and air travel is constrained to baseline scenario trajectories, the GDP loss between a fixed carbon emission trajectory and a baseline scenario is less. This is because early restriction of infrastructure for roads and air travel allows an expansion of public transport infrastructure, which is adequate to meet low-carbon transport service demand, whereas when there is less public transport infrastructure, more costly mitigation investments must be made. This suggests that infrastructural choices could be very important for climate policy costs.

\section{Model comparison studies}

Three model comparison studies in the Special Issue compare transport trends within integrated models, in order to better understand sectoral dynamics that could provide opportunities or barriers to GHG mitigation and to identify key uncertainties across the models.

Edelenbosch et al. (2017a) decompose the projected global passenger transport emission paths of eleven IAMs by their underlying contributions of travel demand, modal shift, efficiency and fuel type used. To compare results across the models and with historic trends, the Laspeyres index decomposition method is utilized. The authors find that the models' baseline scenarios generally show continuing activity increase and improved efficiency over time, thus following historical trends. Mitigating emissions to reach a 2 degree target - in line with the Paris Agreement - is highly dependent on technology change resulting in further efficiency improvements and alternative fuel use, thus going beyond historical observations. Shifting to less carbon-intensive modes or reduced travel are not projected to be the most attractive measures to reduce emissions in these scenarios, but possibly could complement the current radical technology switch required.

The second comparison paper analyses the models' sensitivity to fuel price and income levels, which are key determinants of energy system modelling (Edelenbosch et al., 2017b). To isolate price effects on energy demand, the fuel price is 
shocked over a period of 50 years, and fuel demand responses, in the form of elasticities, are compared across six IAMs. Similarly, income elasticity values are calculated by comparing transport energy demand projections of different income pathways. In the relatively near future (first 10-20 years) the models price elasticity values are comparable to each other and roughly within the range suggested by the empirical literature. However, in the longer term (30-40 years), some models become more responsive to price while others remain at comparable values. Different dynamics lead to the higher sensitivity, such as long response time to fuel price shocks, availability of new technologies, and feedback effects on fuel prices. The paper shows that using price and income elasticities as diagnostic measure to test and compare model behavior is a suitable and transparent method that could also be applied to other end-use energy sectors (e.g., buildings and industry).

Finally, the third transport comparison paper makes the link between integrated assessment models and transport sector-only models (Yeh et al., 2017). In this paper the modelling frameworks, underlying data, assumptions intermediate results, and projections are compared. Strikingly large differences in base-year data and key future projection parameters are found between the models. Examples are passenger and freight activities, modal shares, vehicle ownership rates and modal energy consumption. Moreover, the identified mitigation strategies to reach a 2 degree target differ markedly between the models: the IAM-derived scenarios focus more on fuel switching to low-carbon fuels and efficiency improvement, as seen also in the other model comparison studies, while the scenarios from transport-only models put more of an emphasis on efficiency improvements and modal shifts. The authors conclude that future model improvements should focus on reducing data gaps by improving access to data and coordinating efforts to align historical data and compare input assumptions, and translate policy analysis and modelling insights between the different approaches.

\section{Concluding remarks}

This Special Issue provides a useful overview of the State of the Art in current long-term modelling of the global transport sector in the context of climate policy. Obviously, future research and model development efforts could further increase our understanding in the various areas highlighted herein, as well as in numerous others. In particular, future research would do well to focus on further representing the influence of consumer choice and heterogeneity (including social influence processes), the impact of the rate of technology change, the different ways to induce mitigation, behavioral and lifestyle changes with respect to modal shifts and demand avoidance, and also on the ability to decarbonize parts of the transport sector that have found so-far to be difficult to "decarbonize" (e.g., freight and aviation).

\section{Acknowledgement}

The research leading to these results has received funding from the European Union Seventh Framework Programme FP7/ 2007e2013 under grant agreement no. 308329 (ADVANCE).

\section{References}

Banister, D., 2011. Cities, mobility and climate change. J. Transp. Geogr. 19 (6), 1538-1546.

Broin, E.Ó., Guivarch, C., 2017. Transport infrastructure costs in low-carbon pathways. Transp. Res. Part D: Transp. Environ. 55, 389-403.

Carrara, S., Longden, T., 2017. Freight futures: the potential impact of road freight on climate policy. Transp. Res. Part D: Transp. Environ. 55, 359-372.

Clarke, L., Jiang, K., et al., 2014. Assessing transformation pathways. In: Climate Change 2014: Mitigation of Climate Change. Contribution of Working Group III to the Fifth Assessment Report of the Intergovernmental Panel on Climate Change Cambridge, United Kingdom and New York, NY, USA, International Panel for Climate Change (IPCC).

Creutzig, F., Jochem, P., et al, 2015. Transport: a roadblock to climate change mitigation? Science 350 (6263), 911-912.

Edelenbosch, O., McCollum, D., et al, 2017a. Decomposing passenger transport futures: comparing results of global integrated assessment models. Transp. Res. Part D: Transp. Environ. 55, 281-293.

Edelenbosch, O.Y., Vuuren, D.P.v., et al, 2017b. Assessment of transport demand response to fuel price and income projections in integrated assessment models. Transp. Res. Part D: Transp. Environ. 55, 310-321.

Girod, B., van Vuuren, D., et al, 2013. Climate impact of transportation A model comparison. Clim. Change 118 (3-4), 595-608.

IEA, 2016. Energy Technologies 2016: Towards Sustainable Urban Energy Systems. International Energy Agency, Parics, France.

Karkatsoulis, P., Siskos, P., et al, 2017. Simulating deep $\mathrm{CO}_{2}$ emission reduction in transport in a general equilibrium framework: the GEM-E3T model. Transp. Res. Part D: Transp. Environ. 55, 343-358.

Kriegler, E., Riahi, K., et al, 2015. A short note on integrated assessment modeling approaches: Rejoinder to the review of "Making or breaking climate targets-The AMPERE study on staged accession scenarios for climate policy". Technol. Forecast. Soc. Chang. 99, $273-276$.

Kromer, M.A., Heywood, J.B., 2007. Electric Powertrains: Opportunities and Challenges in the U.S. Light-Duty Vehicle Fleet. Cambridge, USA, Sloan Automotive Laboratory, Laboratory for Energy and the Environment, Massachusetts Institute of Technology.

McCollum, D.L., Wilson, C., et al, 2017. Improving the behavioral realism of global integrated assessment models: an application to consumers' vehicle choices. Transp. Res. Part D: Transp. Environ. 55, 322-342.

Mittal, S., Dai, H., et al, 2017. Key factors influencing the global passenger transport dynamics using the AIM/transport model. Transp. Res. Part D: Transp. Environ. 55, 373-388.

Pietzcker, R.C., Longden, T., et al, 2014. Long-term transport energy demand and climate policy: alternative visions on transport decarbonization in energyeconomy models. Energy 64, 95-108.

Schäfer, A., 2009. Transportation in a Climate-Constrained World. MIT Press.

Sims, R., Schaeffer, R., et al., 2014. Transport. In: Climate Change 2014: Mitigation of Climate Change. In: Edenhofer, O., Pichs-Madruga, R., Sokona, Y., Farahani, E., Kadner, S., Seyboth, K., Adler, A., Baum, I., Brunner, S., Eickemeier, P., Kriemann, B., Savolainen, J., Schlömer, S., von Stechow, C., Zwickel, T., Minx, J.C., (Eds.), Contribution of Working Group III to the Fifth Assessment Report of the Intergovernmental Panel on Climate Change. Cambridge, United Kingdom and New York, NY, USA. International Panel fro Climate Change (IPCC).

Yeh, S., Mishra, G.S., et al, 2017. Detailed assessment of global transport-energy models' structures and projections. Transp. Res. Part D: Transp. Environ. 55, 294-309. 
Detlef P. van Vuuren ${ }^{\mathrm{a}, \mathrm{b}, *}$

Oreane Y. Edelenbosch ${ }^{\mathrm{a}, \mathrm{b}}$

David L. McCollum ${ }^{\mathrm{c}}$

Keywan Riahi ${ }^{\mathrm{c}}$

a PBL Netherlands Environmental Assessment Agency, Bezuidenhoutseweg 30, 2594 AV Den Haag, The Netherlands

${ }^{\mathrm{b}}$ Fac. of Geosciences, Copernicus Institute for Sustainable Development, Utrecht University, Heidelberglaan 2, Utrecht 3584 CS, The Netherlands

${ }^{\mathrm{c}}$ International Institute of Applied System Analysis (IIASA). Schlossplatz 1 - A-2361 Laxenburg, Austria

* Corresponding author at: Fac. of Geosciences, Copernicus Institute for Sustainable Development, Utrecht University, Heidelberglaan 2, Utrecht 3584 CS, The Netherlands. E-mail address: Detlef.vanVuuren@pbl.nl (D.P. van Vuuren)

Available online 1 June 2017 